\title{
Vorbild und aemulatio: \\ An der Kreuzung von intertextuellen Bezügen in den Totenklagen dreier Frauen in Quintus Smyrnaeus' Posthomerica: Briseis, Tekmessa und Oinone*
}

\author{
GeOrgios P. TSOMIS
}

Das Epos Posthomerica, ein Bericht über die Ereignisse des Trojanischen Krieges, die zwischen den Handlungen der Ilias und der Odyssee liegen, verfasste Quintus (3. Jh. n. Chr.) für Angehörige der griechischen Oberschicht, Dichter und Philologen, die Homer, Hesiod, Apollonios Rhodios und klassische Tragödien kannten, gebildet und literarisch interessiert waren. Diese Leser, die wie Quintus selbst Unterricht beim Grammaticus und beim Rhetor, wo die homerischen Epen eine große Rolle spielten, ${ }^{1}$ erhalten und sich dann durch Privatlektüre weitergebildet hatten, waren in der Lage, den Text zu verstehen, ihn zu studieren und die Leistung des Dichters beim Aufbau buchübergreifender Handlungsstränge sowie der Gestaltung der einzelnen Bücher und des Ganzen als Einheit zu erfassen. Im Epos sind Anspielungen auf Stellen eigener Werke und die anderer Dichter mehr oder weniger deutlich. Solche Textstellen, jeweils als Teileinheit eines bestimmten Zusammenhangs gestaltet, waren dem eigenen Kontext so anzupassen, dass dieser Text unabhängig von den Anklängen widerspruchsfrei und sinnvoll war. Erst durch Erforschen ihrer Funktionen und Erfassen der intertextuellen Beziehungen wird also ein tieferes Verständnis gewonnen. ${ }^{2}$ Wie Riffa-

* Frau Nicola Dümmler und den Herren Manuel Baumbach, Silvio Bär und Thomas A. Schmitz spreche ich meinen Dank für ihre Anregungen aus. Was die Texte aus den Posthomerica betrifft, verwende ich in dieser Studie die Ausgaben von Vian $(1963 ; 1966 ; 1969)$ und von Pompella (2002). Texte aus der Ilias werden nach der Ausgabe von West (1998; 2000), aus der Odyssee nach der von Allen $\left({ }^{2} 1917 ;{ }^{2} 1919\right)$ zitiert. Für den Text von Sophokles benutze ich die Ausgabe von Dawe $(1975 ; 1979)$.

1 Vgl. Pseudo-Plutarch, Vita Homeri (wahrscheinlich im späten 2. Jh. verfasst); Hillgruber (1994) 5-35; Lamberton (2002) 195, 205; North (1952) 1-33; Marrou ( $\left.{ }^{6} 1977\right)$ 311-312; Bonner (1977) 227-249; Verdenius (1970); Robb (1994) 159-182; Fernández (1994) 299-305; Morgan (1998) 219-226; Nilsson (1955) 96. Zu der Ethopoiia mit Themen aus dem Trojanischen Kreis siehe Ureña (1999) 315-339.

2 Vgl. Puccis (1998a) 18 Bemerkungen: „[Allusion] denotes a source text and specifies some discrete, recoverable property(ies) belonging to the intention of this source text (or specifies its own property(ies) in the case of self-echo); the property(ies) evoked modifies the alluding text, 
terre bemerkt, ist das intertextuelle Lesen ein Verfahren, das die Suche nach „comparabilities from text to text" fördert. ${ }^{3}$

Im Folgenden möchte ich dieses Verfahren exemplarisch auf die Klagen von Briseis, Tekmessa und Oinone um den Tod der von ihnen geliebten Männer anwenden. Quintus ist solchen yóor „Trauerreden“ von Frauen über Helden schon in der Ilias begegnet: derjenigen der Briseis um Patroklos in Buch 19 (287-300) und von Hekabe, Andromache und Helena um Hektor in Buch 22 (431-436; 477516) und 24 (725-745; 748-759; 762-775). ${ }^{4}$ Briseis ist in der Ilias eine Beutefrau,

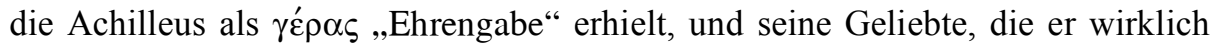
liebt (vgl. Il. 9.341b-343). Ihre Wegnahme durch Agamemnon im 1. Buch hat weitreichende Folgen: Sie verursacht den Streit zwischen dem Oberbefehlshaber

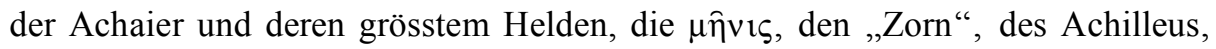
sowie die zeitweilige Überlegenheit der Troer während Achilleus' Kampfenthaltung, die zur Tötung seines besten Freundes Patroklos durch Hektor führt. Die Posthomerica setzen diese Geschehnisse voraus. Tekmessa begegnet uns erstmals in Sophokles' Aias. Hier ebenso wie bei Quintus hat Aias sie im Kampf erbeutet, zu seiner Konkubine gemacht und mit ihr Eurysakes gezeugt. Oinone, auf die zuerst Lykophron, Alexandra 57-68 anspielt, ist die erste Gemahlin des Paris. Er verlässt sie um Helenas willen. Nach seiner schweren Verwundung durch Philoktetes bittet Paris sie um Heilung. Sie weist ihn ab. In älteren Versionen ${ }^{5}$ wird sie danach von Reue erfasst und eilt zu ihm, um ihn zu retten, kommt aber zu spät und tötet sich. Quintus hat diesen Ausgang neu gestaltet.

Durch Text- und Strukturanalyse möchte ich zeigen, dass die Totenklagen der drei Frauen nach einem eigenständigen poetischen Plan verfasst worden sind und hierzu auch Anspielungen auf fremde und eigene Stellen gehören. Das Erkennen der Anspielungen soll den Lesern nicht nur Vergnügen bereiten, sondern sie auch zu geistigem Bemühen um die Erfassung von deren jeweiliger Funktion, also zu einer besonderen Rezeptionshaltung bewegen.

and possibly activates further, larger inter- and intra-textual patterns of properties with the consequent further modifications of the alluding text." Müller (1991) 107 führt den neuen Begriff ,interfigurality“ ein und nennt die betreffenden Textelemente ,re-used figures“: „We speak of ,re-used figures" in order to indicate that if an author takes over a figure from a work by another author into his own work, he absorbs it into the formal and ideological structure of his own product, putting it to his own uses, which may range from parody and satire to a fundamental revaluation or reexploration of the figure concerned."

3 Vgl. Riffaterre (1980) 626-627.

$4 \mathrm{Zu}$ den róot in der Ilias vgl. neuerdings die Arbeit von Tsagalis (2004).

5 Vgl. Parth. 4 (in der kommentierten Ausgabe von Lightfoot [1999]); Conon 23 (in der kommentierten Ausgabe von Brown [2002]); [Apollod.] 3.154-155. 


\section{Briseis’ Klage (Q.S. 3.551-581)}

Nur den Tod von Achilleus (3. Buch), Aias (5. Buch) und Paris (10. Buch) beklagen mehrere Einzelpersonen in Reden, und nur die Bestattung dieser Helden wird anschließend geschildert. ${ }^{6}$ Die Totenklagen um Achilleus umfassen 271, die um Aias 100 und die um Paris 59 Verse. Der gefallene Achilleus wird zuerst von Männern, die zum Teil Reden halten, ${ }^{7}$ dann von menschlichen Frauen und schließlich auch von seiner göttlichen Mutter betrauert, mit Reden nur von Briseis und Thetis. Agamemnons Beschreibung (Od. 24.43-97) erwähnt die weiblichen Gefangenen des Helden nicht. In den Posthomerica 3.544-550 berichtet der Erzähler am Anfang des zweiten Teiles, dass die Frauen, die Achilleus bei der Eroberung von Lesbos und Thebe, der kilikischen Stadt Eëtions, erbeutet hatte, seine Leiche betrübt umstanden, gejammert, ihre schöne Haut zerkratzt und mit Schlägen auf ihre Brüste den Peliden von Herzen betrauert hätten, weil er sie,

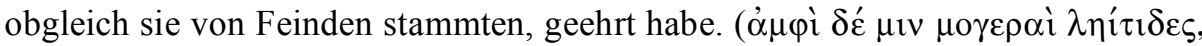

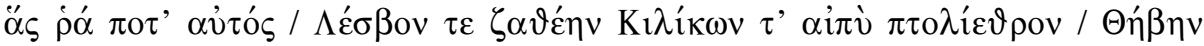

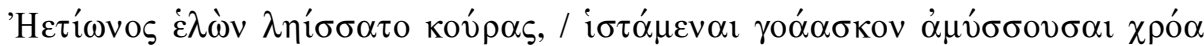

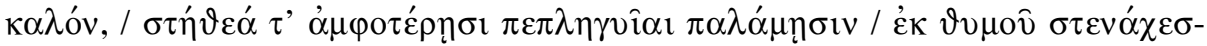

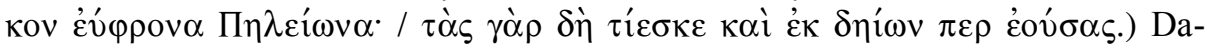
nach tritt Briseis bei Quintus zum ersten Mal auf. Die Darstellung ihrer Trauer besteht aus drei Teilen: 3.551-558, 559-573, 574-581. Zunächst wird Briseis über die anderen Frauen erhoben: Sie, die Bettgenossin des Achilleus, sei am allermeisten im Herzen bekümmert gewesen, um den Toten herumgelaufen, habe mit beiden Händen ihre schöne Haut zerkratzt und geschrien. Auf ihrer zarten Brust seien durch Schläge blutige Striemen hervorgetreten; man hätte sagen können, rotes Blut ergieße sich in Milch. Trotz ihrer schmerzvollen Trauer habe ihre Schönheit liebreizend geglänzt und Anmut habe ihre Gestalt umgeben. (3.551-

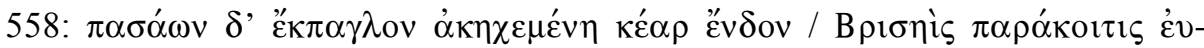

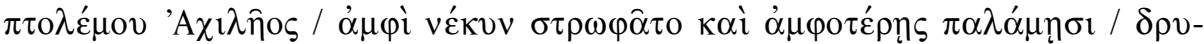

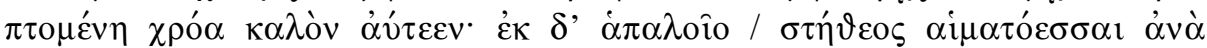

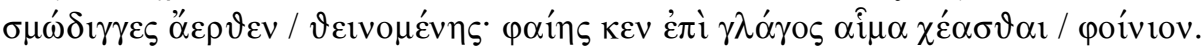

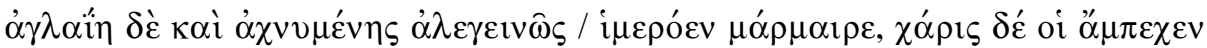
عî́os.) Quintus erinnert hier an die Ilias-Partie 19.282-285:

6 Im 1. Buch wird auch die Bestattung von Penthesileia geschildert (1.789-810), aber der Dichter widmet ihrem Tod keine Totenklagen von einzelnen Personen.

7 Q.S. 3.400-421: allgemeine Klage; 3.422-426: Klage der Myrmidonen; 3.427-458: Klage des Aias; 3.460-490: Klage des Phoinix; 3.491-503: Klage des Agamemnon; 3.504-513: allgemeine Klage. 


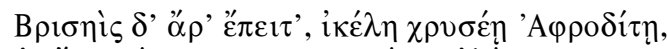

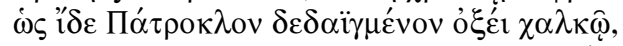

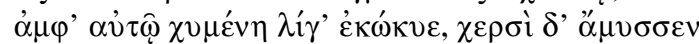

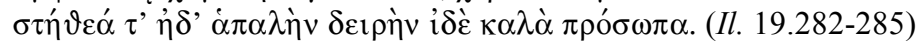

Doch Briseis darauf, gleichend der goldenen Aphrodite,

Wie sie den Patroklos sah, zerfleischt von dem scharfen Erz,

Über ihn hingegossen schrie sie hellauf und zerkratzte mit den Händen

Sich die Brüste und den zarten Hals und das schöne Antlitz. ${ }^{8}$

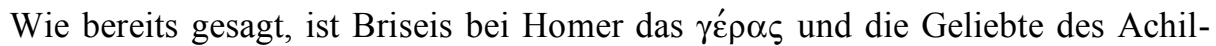
leus, nicht des Patroklos. Dennoch wirft sie sich, sobald sie dessen Leiche erblickt hat, auf den Toten, stößt Klageschreie aus und zerkratzt ihre Brüste, ihren Hals und ihr Gesicht. Vor allem ihre Berührung der Leiche mit ihrem ganzen Körper weist darauf hin, dass sie Patroklos sehr zugetan war. Dies versteht sich nicht von selbst und wird erst durch ihre folgende Rede erklärt (Il. 19.287-300; s.u. S. 189190). Betrachtet man die Schilderung bei Quintus vor dem Hintergrund der IliasStelle, erkennt man, dass Briseis um Achilleus tiefer trauert nicht nur als die anderen Beutefrauen, sondern auch als um Patroklos bei Homer, weil er ihr mehr

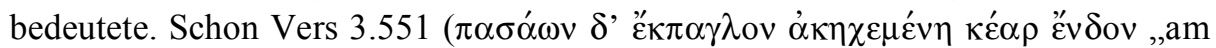
allermeisten im Herzen bekümmert") erwähnt ihren besonders großen Kummer. Im folgenden Vers wird sie als $\pi \alpha \rho \alpha ́$ коı $\iota \varsigma$ „Bettgenossin“ des Achilleus bezeichnet. Aber dass sie seine Bettgenossin - nicht seine Ehefrau - war, reicht nicht aus, um ihr verzweifeltes Verhalten an seiner Leiche zu erklären. Sie wirft sich zwar nicht auf den Toten wie bei Homer, aber im Unterschied zu den ande-

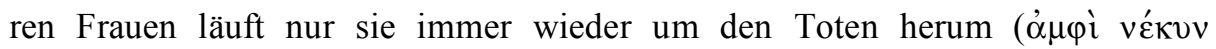
$\sigma \tau \rho \omega \varphi \hat{\alpha} \tau o$ [3.553] ruft äußere und innere Unruhe hervor), nur sie stößt wie in der Ilias Schreie aus, während sie sich zerkratzt. ${ }^{9}$ Nur sie schlägt so hart auf ihre zarte $^{10}$ Brust, dass darauf blutige Striemen entstehen. All dies zeigt schon vor ihrer Rede ihre Liebe zu Achilleus. Der Dichter weist aber mit $\chi \rho o ́ \alpha ~ \kappa \alpha \lambda o ́ v$ „schöne Haut“ und $\dot{\alpha} \pi \alpha \lambda$ oîo $\sigma \tau \eta \dot{\vartheta} \varepsilon$ cos ,zarte Brust“ (3.554-555) auch auf ihre Schönheit hin. Zu demselben Zweck vergleicht er die blutigen Striemen auf ihrer Brust mit Blut, das sich in Milch ergießt (3.556-557). ${ }^{11}$ Weiße Brüste erregen

8 Übersetzung von Schadewaldt (1975). Soweit nicht gesondert bezeichnet, stammen alle Übersetzungen von mir.

9 Zu dieser Partie vgl. etwa Opp. C. 1.494-501 (Gleichnis).

10 Zum Adjektiv $\dot{\alpha} \pi \alpha \lambda \operatorname{ó}_{\varsigma}$ bzw. $\dot{\alpha} \pi \alpha \lambda \hat{\alpha}^{\alpha} \chi \rho \operatorname{loo}$, das für junge Menschen gebraucht wird, vgl. Sapph.

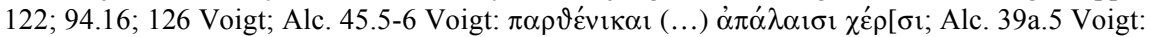

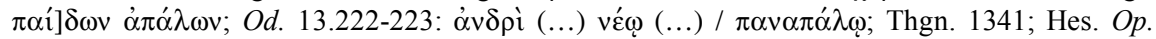
519; h.Ven. 14.

11 Ebenso vergleicht Homer (Il. 4.141-147) das auf die Beine bis zu den Knöcheln hinabfließende Blut des Menelaos mit der Purpurfärbung von Elfenbein, durch die ein Backenstück für Pferde

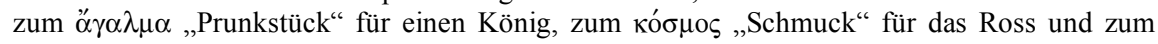


erotisches Verlangen. Die weiße Farbe ist ein Topos zur Bezeichnung einer attraktiven schönen Haut von Frauen und Jungen. ${ }^{12}$ Die Vorstellung der dunkelroten Farbe auf weißer Haut, die wir in Bions Adonis 9-10 und 25-27 (dunkelrotes Blut auf weißer Haut) finden, ${ }^{13}$ ist in der späteren Literatur für attraktives Erröten eines Menschen adaptiert. ${ }^{14}$ Der neu gebildete Vergleich bei Quintus (3.556b557a) ersetzt den formelhaften in der homerischen Partie in Briseis' Klagerede

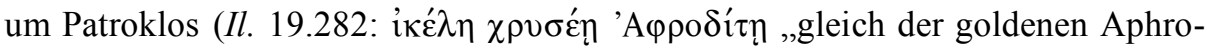
dite") und bereitet den unmittelbar folgenden, die Schilderung abschließenden Lobpreis vor (3.557-558), dass nämlich die $\alpha \gamma \lambda \alpha \ddot{\eta} \eta$ „Schönheit“" der Briseis trotz ihres schmerzvollen Kummers liebreizend geglänzt und dass $\chi \alpha$ ’ Gestalt umgeben habe. Diese Schönheit und Anmut, die durch Unglück und Verzweiflung nicht beeinträchtigt werden, erklären, warum Achilleus Briseis zu seiner $\pi \alpha \rho \alpha ́$ коı $\tau \varsigma$ erhob und damit vor allen anderen gefangenen Frauen auszeichnete. Die eben behandelte Schilderung bietet uns schon ein kleines Beispiel der aemulatio des Quintus. Ich möchte in den Versen 3.557-558 das Bestreben des Dichters, Briseis als schöne und würdige Braut des Achilleus darzustellen eine nunmehr unerfüllbare Vorstellung -, nicht ausschließen. Man vergleiche etwa das Fragment des Sapphischen Epithalamios 112 Voigt, in dem die Dichte-

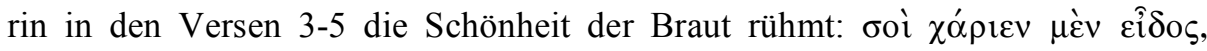

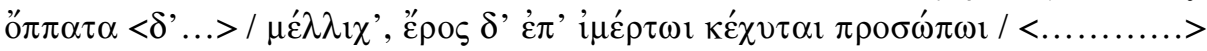

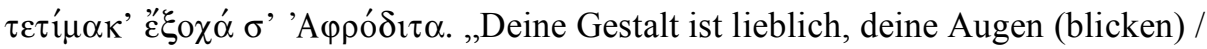
zärtlich, dein liebliches Antlitz ist von Eros übergossen. / (...) Aphrodite hat dir große Ehre geschenkt."“

Bei der Abfassung der folgenden Klagerede der Briseis (3.560-573) wandelte der Dichter ihre Rede an der Leiche des Patroklos (Il. 19.287-300) ab. Diese lautet:

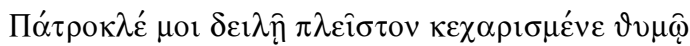

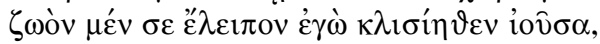

vôv $\delta \varepsilon^{\prime} \sigma \varepsilon \tau \varepsilon \vartheta v \eta \hat{\omega} \tau \alpha \kappa \imath \chi \alpha \dot{\alpha} \nu \mu \alpha \iota$ ó $\rho \chi \alpha \mu \varepsilon \lambda \alpha \hat{\omega} v$

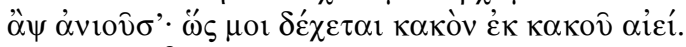

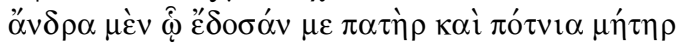

290

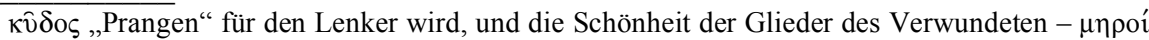

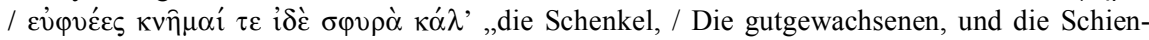
beine und die Knöchel, die schönen" (Übersetzung von Schadewaldt [1975]) - hervorhebt. Vgl. dazu Fränkel (1921) 54-55.

12 Vgl. Prop. 2.9.10 für Briseis, die den entseelten Achilleus umarmt: candida vesana verberat ora manu ,sie schlug mit rasender Hand ihr strahlend weißes Gesicht" (Übersetzung von Mojsisch / Schwarz / Tautz [1993]).

13 Auf diese zwei Stellen verweist Vian (1963) 117. Vgl. auch Q.S. 1.60; 14.41.

14 Vgl. z.B. $A P$ 5.35.5-6 (Rufin.); AP 5.84.1-2; Ov. Am. 3.3.5-6; Ov. Met. 3.423; [Tib.] 3.4.30; Nonn. D. 4.130-132. Dazu siehe Reed (1997) 200, 212-213. 


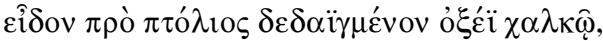

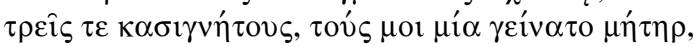

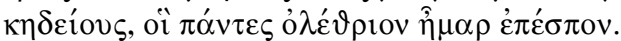

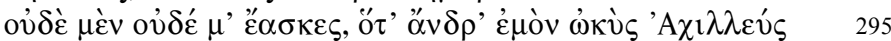

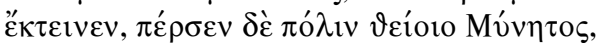

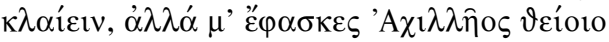

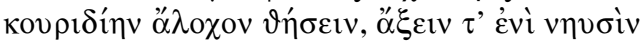

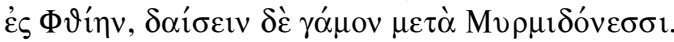

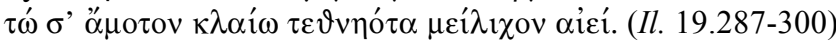

Patroklos, mir, der Unglücklichen, in meinem Herzen der Liebste,

als Lebenden verließ ich dich, als ich aus der Hütte wegging,

jetzt aber bei meiner Rückkehr finde ich dich tot, Gebieter von Männern.

Wie folgt für mich immer Unglück auf Unglück!

Meinen Mann, den mein Vater und meine ehrwürdige Mutter mir gegeben hatten,

erblickte ich vor der Stadt von scharfem Erz getötet,

und auch die drei teuren Brüder, die mir eine einzige Mutter geboren hatte,

sie alle hatte der Tag des Verderbens erreicht.

Aber du ließest mich nicht weinen, als der schnelle Achilleus meinen Mann

getötet und die Stadt des göttlichen Mynes zerstört hatte,

sondern du erklärtest, du würdest mich zur Ehefrau des göttlichen Achilleus

machen und zu Schiff nach Phthia bringen

und das Hochzeitsmahl unter den Myrmidonen richten.

Deshalb beklage ich unablässig deinen Tod, du immer Freundlicher.

Bei Quintus (3.560) beginnt Briseis nicht mit einer preisenden apostrophe an den Toten, sondern mit einem pathetischen Ausruf, der sich nur auf ihr eigenes Leid

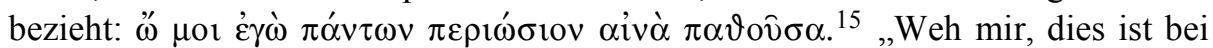
weitem das schlimmste aller meiner Leiden." Schon mit diesen Worten bekundet sie ihre Liebe zu Achilleus. Danach begründet sie den Ausruf und redet den Toten an: Niemals sonst habe sie so großes Leid befallen, weder um ihre Brüder noch

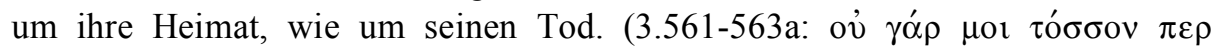

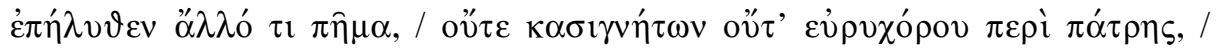

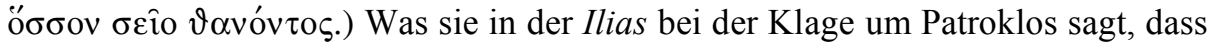
sie ihren Gatten, ihre Brüder und ihre Heimat durch Achilleus verlor, das verschweigt sie hier, weil sie ihm keinen Vorwurf machen will, und stellt seinen Tod als ihr größtes Leid hin. ${ }^{16}$ Denn er sei für sie der heilige Tag, ${ }^{17}$ das Licht der

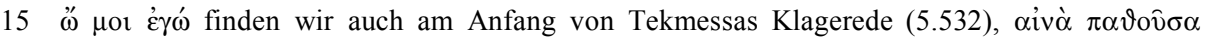
kommt bei Quintus nur hier, bei Homer in der Klage der Hekabe um den toten Hektor (Il. 22.431) vor.

16 Es ist hier von Bedeutung, dass sie von Mördern und Eroberern schweigt. Sie beabsichtigt, Achilleus als Verursacher ihrer $\pi$ í $\mu \alpha \tau \alpha$ „Leiden“ im Hintergrund zu lassen. In dieser Hinsicht ist es charakteristisch, dass der Dichter weder in der allgemeinen Klage der Sklavinnen (3.544550), wo er ihre Herkunftsländer aufzählt, noch in der einleitenden Partie der Klage der Briseis die Heimat der Briseis erwähnt. Die Eroberung von Lyrnessos und die Tötung von Briseis' 
Sonne, das süße Leben, ${ }^{18}$ die Hoffnung auf Gutes und der gewaltige Schutz vor Betrübnis gewesen, viel wertvoller als jede Pracht und die Eltern: All dies war

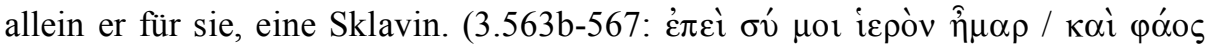

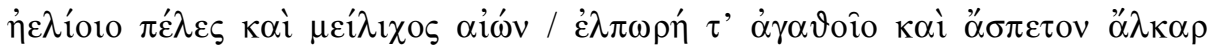

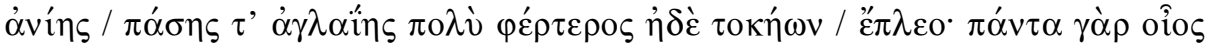

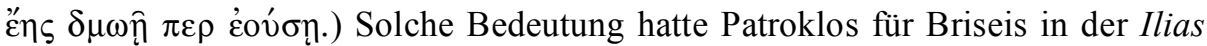
nicht. Er war dort für sie der freundliche Mann, der sie nach der Eroberung ihrer Stadt und dem Verlust ihrer Angehörigen tröstete und ihr das Versprechen gab, sie mit Achilleus zu vermählen.

Die Verse 3.561-568 rufen auch die berühmte Szene der Homilia zwischen Hektor und Andromache im 6. Buch der Ilias ins Gedächtnis. Speziell die Verse 3.561-563 erinnern an Hektors Worte zu Andromache (Il. 6.450-465), mit denen er ihr versichert, dass sie ihm vor allen, auch vor Mutter, Vater und Brüdern, am Herzen liege und er sich um ihr Los sorge, wenn er sterbe und Troja erobert werde, eine für ihn sichere Annahme (Il. 6.447-449). Kurz zuvor, nachdem Andromache ihm erzählt hat, wie sie ihre Heimat und ihre ganze Familie verloren

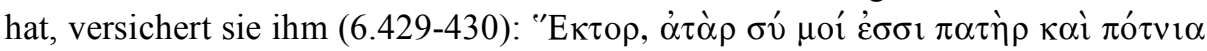

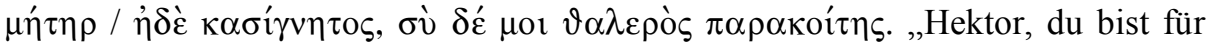
mich Vater und ehrwürdige Mutter / und Bruder, du bist für mich der blühende Bettgenosse." Briseis' Lobpreis des Achilleus erinnert an diese Worte der Andromache. Bei Quintus war Achilleus für Briseis nicht nur Ersatz für ihre Eltern und ihren Bruder und zugleich ihr Ehemann, sondern schlichtweg all das, was dem Leben Licht - im wörtlichen und übertragenen Sinne - verleiht. In Vers 3.568 fügt sie hinzu, dass er sie auch zu seiner Bettgenossin gemacht und von

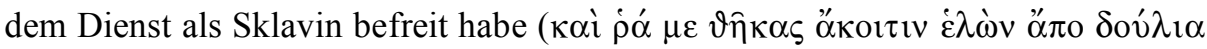
$\varepsilon^{\prime} \rho \gamma \alpha$ ). Andromache bringt ihre schmerzliche Vergangenheit in Erinnerung, um Mitleid bei der Person, von der sie abhängig ist, ihrem Gatten Hektor, zu erwecken, damit er sich von der Schlacht fern hält und sein Leben rettet. Die iliadische Briseis erinnert wiederum an ihre früheren $\kappa \alpha \kappa \alpha ́$, um zu zeigen, dass sie die einzige Bezugsperson, Patroklos, die sie zur Vermählung mit Achilleus führen würde, schon verloren habe. Anstelle der Ehe mit Achilleus und eines neuen

\footnotetext{
Vater durch Achilleus werden in Q.S. 4.477-478 ohne einen Hinweis auf Briseis beiläufig genannt. Auch für den homerkundigen Leser ist von Bedeutung, dass in der Ilias (19.293-294) nicht ausdrücklich gesagt wird, dass ihre Brüder von den Händen des Achilleus getötet wurden.

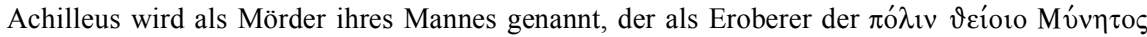
„der Stadt des göttlichen Mynes“ agiert (Il. 19.295-296). Quintus lässt die Erwähnung des Todes ihres rechtmäßigen Gatten, welchem Homer insgesamt drei Verse widmet (Il. 19.291292; 295b-296a), auch aus diesem Grunde weg, d.h. er will in der Rede der Briseis eine negative Charakterisierung des Achilleus vermeiden.

17 iepòv $\hat{\eta} \mu \alpha \rho$ „,heiliger Tag“ (3.563): formelhaft bei Homer, nur hier in den Posthomerica.

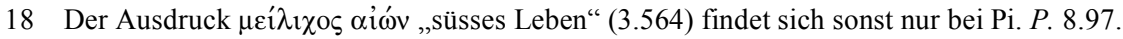


glücklichen Lebens sieht die homerische Briseis in der Tötung des Patroklos das allmähliche Erlöschen ihrer Hoffnungen auf ein neues Leben. Obwohl Briseis den toten Patroklos in der Ilias beklagt, ist ihr Glück allein von der Rettung des Achilleus abhängig: ${ }^{19}$ Mit dieser Rede appelliert Briseis also indirekt an das Mitleid des Achilleus, wobei er in der Ilias keinerlei Versicherung über ihr künftiges Los ausspricht. ${ }^{20}$

Indem Quintus auf die berühmte eheliche Homilia zwischen Hektor und Andromache anspielt, erweckt er den Eindruck, Briseis beweine ihren Ehemann, den sie mit ihrem Lobpreis, der einem Makarismos gleichkommt, als solchen rühme. Briseis beabsichtigt somit, das Mitleid der Achaier zu erwecken, damit sie nicht als Sklavin mit allen schlimmen Folgen behandelt wird. Sie fürchtet also, in den Status der Sklaverei zurückzufallen.

Dieser Sorge gibt sie gleich danach, im letzten Teil ihrer Rede, Ausdruck: Jetzt werde ein anderer Achaier sie zu Schiff nach Sparta oder Argos bringen, und als Magd werde sie schlimme Leiden erdulden, weil sie des Achilleus beraubt sei.

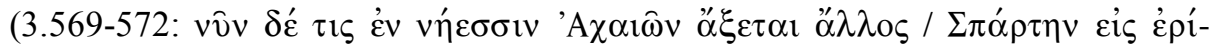

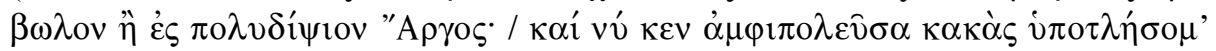

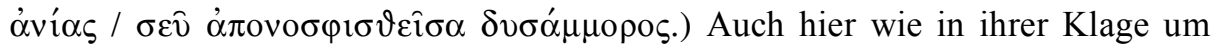
Patroklos finden wir die Vorstellung, zu Schiff nach Griechenland gebracht zu werden, aber nun in extremem Gegensatz zu der von Patroklos versprochenen Fahrt nach Phthia zur Feier ihrer Vermählung mit Achilleus. In der Ilias erwägt Briseis nicht die Möglichkeit, als Sklavin nach Griechenland geführt zu werden. Sie hat zwar Patroklos, der ihr durch sein Intervenieren neues Leben und künftiges Glück gewährleisten könnte, verloren, aber Achilleus, ihre letzte $\varepsilon \lambda \lambda \pi \omega \rho \eta$ „Hoffnung“, ist noch am Leben. Nunmehr ist diese $\dot{\varepsilon} \lambda \pi \omega \rho \eta \dot{~} \tau$ ' $\alpha \gamma \alpha \vartheta \hat{o}$ o ,die Hoffnung auf Gutes“ (3.565) dahin; sie wird auf den Schiffen nach Griechenland geführt werden, aber nicht nach Phthia und nicht mit Achilleus an ihrer Seite. Irgendein $\alpha \alpha \lambda \lambda$ o , ,anderer“ (3.569) wird sie als Sklavin nach Sparta oder Argos

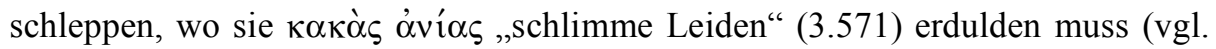

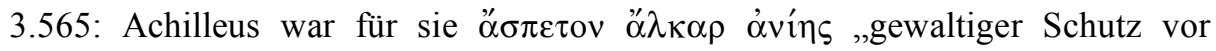

19 Vgl. auch Tsagalis (2004) 87.

20 Der homerkundige Leser weiß, dass Achilleus, wenn die Götter ihn am Leben erhalten und er in die Heimat gelangt, eine achaiische Frau aus den vielen Töchtern erhabener Fürsten, die Peleus für ihn aussuchen würde, erwählen und zur trauten Gemahlin machen würde (Il. 9.393-397). Auch in der Totenklage des Achilleus um Patroklos (Il. 19.315-337) findet man keine Versicherung. Il. 19.328-333 bietet eine indirekte Antwort auf die Hoffnungen der Briseis vor Patroklos' Tod: Da Achilleus wusste, dass er in Troja sterben sollte, hatte er eine andere Aufgabe für Patroklos geplant, nämlich die Heimkehr seines Sohnes Neoptolemos aus Skyros nach Phthia zu bewirken. Dies schließt m.E. nicht die Hoffnung der Briseis aus, dass Patroklos Achilleus das Versprechen abnehmen könnte, Briseis nach Phthia heimzuführen und zu ehelichen. Zur Beziehung zwischen dieser Rede der Briseis und der Klage des Achilleus um Patroklos siehe Lohmann (1988) 13-32; Pucci (1998a); Tsagalis (2004) 139-143. 
Betrübnis“), genauso wie Hektor die Gefangenschaft Andromaches fürchtet und sich vorstellt (Il. 6.454b-458).

Briseis schließt mit dem zu ihrer Trauer und Befürchtung passenden Ausruf

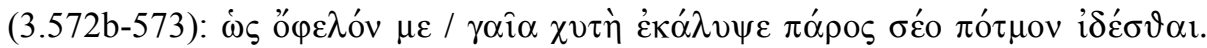
„Hätte mich doch / ein Grabhügel bedeckt, bevor ich deinen Tod erlebte!“ Der Dichter wiederholt hier mit geringfügiger Änderung den Wunsch des Phoinix. ${ }^{21}$ An beiden Stellen und in der Klage Tekmessas (5.537-538) variiert er Hektors Wunsch. ${ }^{22}$

Diese Rede weist also Beziehungen zur Homilia und zur Klage der Briseis in der Ilias auf, aber keine Nachahmung. Bei Quintus hat der Kummer der Briseis und ihre Liebe zu Achilleus nicht dieselben Gründe wie die der Andromache (Hektor) oder die der iliadischen Briseis (Patroklos). Der Vergleich, zu dem die Anspielungen den homerkundigen Leser einladen, lässt die Neuheit dieser Gründe und eine neue Seite des Achilleus hervortreten.

Im letzten Teil der Trauerdarstellung der Briseis spricht wieder der Erzähler.

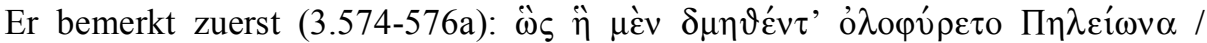

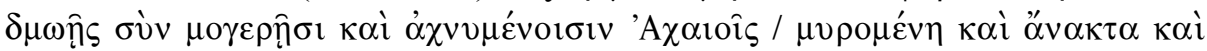
$\alpha v \varepsilon \rho \alpha$. „So klagte sie zusammen mit den tief betrübten Dienerinnen und den bekümmerten Achaiern um den getöteten Peliden / und beweinte ihren Herrn und Mann." ${ }^{23}$ Bei Homer heißt es im Anschluss an die Rede der Briseis (Il. 19.301-

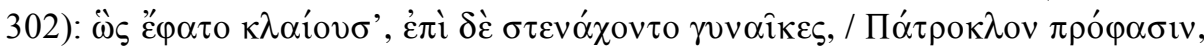

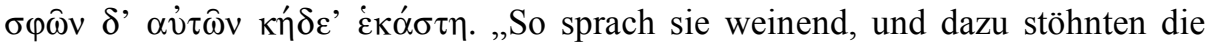
Frauen / scheinbar um Patroklos, doch jede über ihre eigenen Leiden." Bei Quintus trauern die anderen Beutefrauen wirklich um Achilleus. Briseis weint erst jetzt. Dieses Weinen wird besonders hervorgehoben: Ihre Tränen seien niemals getrocknet, sondern dauernd auf den Boden geflossen, wie wenn dunkles Wasser aus einer Felsenquelle hinabfließt, über der viel Reif und Schnee auf dem rauhen Boden ausgebreitet ist, und rings schmilzt der Reif durch den Ostwind und die

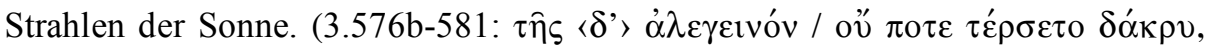

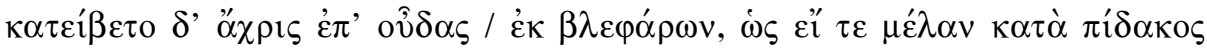

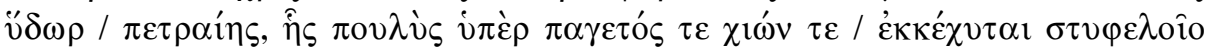

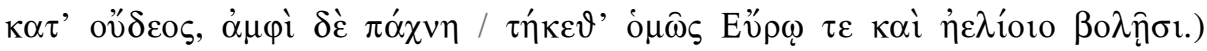
Dieses Gleichnis, mit dem der dritte Teil endet, erinnert an drei Homerstellen: Im

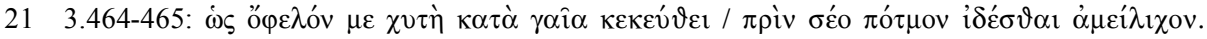
„Hätte mich doch ein Grabhügel bedeckt, / bevor ich dein grausames Geschick erlebte.“

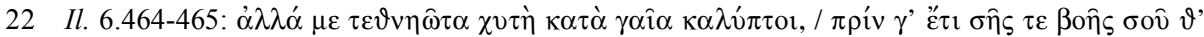
$\dot{\varepsilon} \lambda \kappa \eta \vartheta \mu$ oîo $\pi v \vartheta \varepsilon \dot{\varepsilon} \sigma \vartheta \alpha$. ,Aber mag mich doch, gestorben, die aufgeschüttete Erde decken, / Ehe ich deinen Schrei vernähme und deine Verschleppung." (Übersetzung von Schadewaldt [1975]). Vgl. auch Q.S. 1.109; 7.656-657.

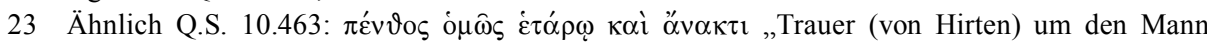
(Paris), der zugleich Gefährte und Herrscher war“. 
9. Buch der Ilias steht Agamemnon in einer Versammlung der Achaier auf, Tränen vergießend, wie eine Quelle mit schwarzem Wasser, die einen steilen

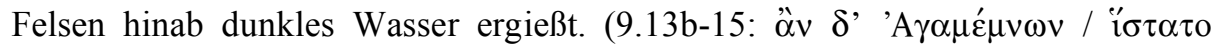

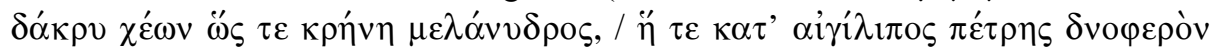

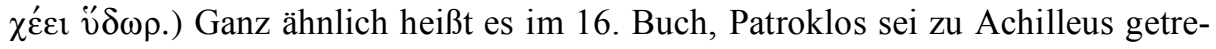
ten, heiße Tränen vergießend, wie eine Quelle mit schwarzem Wasser, die einen

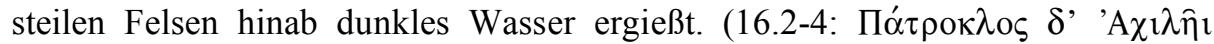

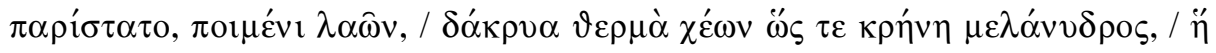

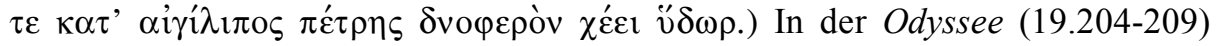
vergießt Penelope Tränen, als sie die Erzählung des scheinbaren Bettlers von seiner Begegnung mit Odysseus anhört, und beim Weinen schmelzen ihre schö-

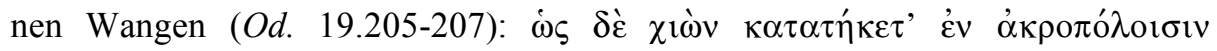

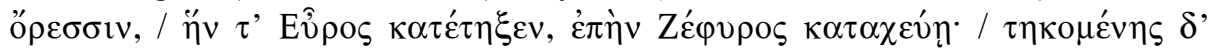

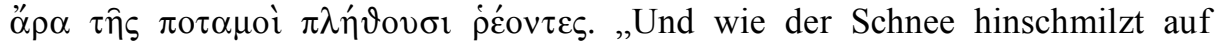
hochstrebenden Bergen, / Den der Ostwind hinschmolz, wenn der West ihn herabschüttet, / Und von dem schmelzenden füllen sich die Flüsse, die strömenden. “24

Quintus hat aus Motiven dieser Gleichnisse und eigenen ein neues geschaffen und ihm einen neuen Sinn gegeben. Denn bei ihm weint Briseis nicht wie Agamemnon und Patroklos über eine Notlage der Achaier oder wie Penelope über den vermeintlichen Verlust ihres Gatten, der in Wahrheit bei ihr sitzt, sondern über den tatsächlichen Tod ihres Herrn und Liebhabers Achilleus. Dieses Weinen ist die dritte Ausdrucksform ihres Leides. Nach Selbstmisshandlung und jammernden Worten entspannt sich ihr Schmerz, indem er Tränen erzeugt, wie Reif und Schnee in dem Gleichnis schmilzt und das schwarze Wasser der Quelle fließen lässt. Auch hier hat der Dichter homerische Vorbilder zu seinem Zweck umgestaltet. Mit dem Gleichnis klingt die Briseis-Partie aus.

Die Klagerede der Briseis in den Posthomerica bildet eine Weiterführung ihrer Totenklage um Patroklos in der Ilias und zugleich eine kritische Auseinandersetzung mit der Ilias-Partie. Zieht der Leser in Betracht, welche Beziehung Patroklos wirklich zu Briseis hatte und was eigentlich Achilleus für sie bedeutete, stellt er den Versuch des Dichters fest, seine Totenklage der Briseis der der homerischen gegenüberzustellen und zu zeigen, dass ihre Klage hier in den Posthomerica intensiver und bedeutender ist als die in der Ilias. Der Leser soll m.E. die Intention des Dichters nachvollziehen, dass der Platz einer Totenklage dieser Sklavin hier in den Posthomerica angemessener ist als in der Ilias.

24 Übersetzung von Schadewaldt (1958). 


\section{Tekmessas Klage (Q.S. 5.521-558)}

Im 5. Buch der Posthomerica begeht Aias, Telamons Sohn, wie in der gleichnamigen Tragödie des Sophokles Selbstmord (Q.S. 5.482-486), weil er erkennt, dass er in gottgesandtem Wahnsinn Schafe getötet hat statt der Achaier, die trotz seiner Verdienste die Waffen des Achilleus nicht ihm, sondern Odysseus zugesprochen haben. Den Göttern verhasst und ehrlos bei den Menschen, will er nicht weiterleben. Anders als bei Sophokles deutet er seine Absicht, sich zu töten, weder Tekmessa noch sonst jemandem an. Auch der von Sophokles dargestellte Versuch der Atriden, seine Bestattung zu verhindern, fehlt bei Quintus: Hier kommen alle Danaer zur Leiche des Aias und trauern um ihn. Sein Tod wird von Teukros, Tekmessa, Agamemnon, Odysseus und Nestor mit Reden beklagt. Da ich mich hier auf die Rede der Tekmessa konzentriere, möchte ich vorab erwähnen, dass wir in Sophokles' Aias eine große Bittrede dieser Frau (Soph. Aj. 485524), mit der sie den Helden vom Selbstmord abzuhalten sucht, und nach seinem Tode einzelne Klagen, aber keine zusammenhängende Trauerrede wie bei Quintus finden. Vor der Mitteilung des Wortlautes dieser Rede schildert der Erzähler nicht nur, wie im Fall der Briseis, das Verhalten Tekmessas an der Leiche, sondern charakterisiert auch ihre Beziehung zu Aias.

Diese Frau erscheint in den Posthomerica erstmals in 5.521 als $\delta \hat{\imath} \alpha$

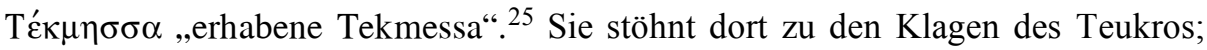
schon dies zeigt ihre Zugehörigkeit zur Familie des Toten. Danach bezeichnet der

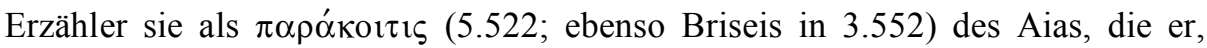
obwohl sie eine Beutefrau gewesen sei, zu seiner Gattin und zur ő $\alpha \alpha \sigma \sigma \alpha$ „Herrin“ (5.523) 26 über all das gemacht habe, wofür die mit Brautgeschenken gefreiten Frauen im Hause bei ihren Ehemännern sorgten. (5.521-525: $\hat{\eta} \dot{\rho} \alpha \mu \varepsilon^{\prime} \gamma \alpha$

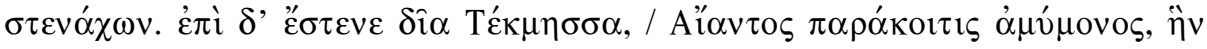

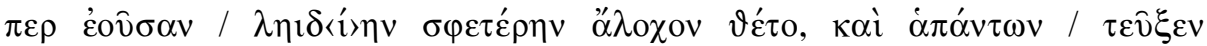

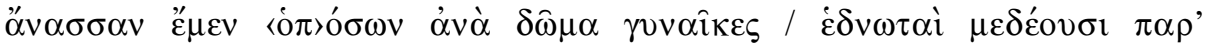

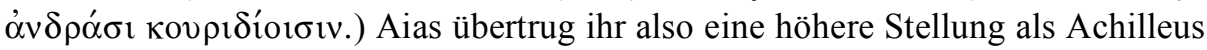
der Briseis. Das ist gegenüber Sophokles neu. Dort erklärt sie (Soph. Aj. 489):

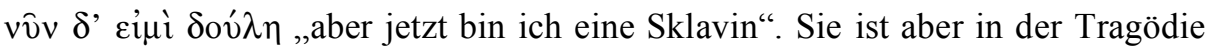
auch die Bettgenossin des Aias und die Mutter seines Sohnes Eurysakes. Bei Quintus heißt es: Sie gebar dem Aias einen Sohn, Eurysakes, der dem Vater in

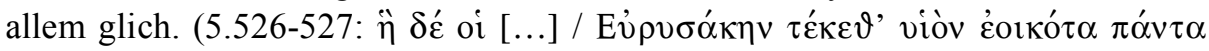

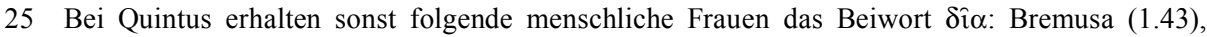
Neaira (1.292), Penthesileia (1.672), Ariadne (4.387), Astyoche (6.135), Kreusa (8.82), Laodike (13.550), Kassandra (14.20).

26 öv $\alpha \sigma \sigma \alpha$ wird noch zweimal für Tekmessa verwendet: 5.542 und 5.548. Das Wort $\alpha^{\prime} \alpha \sigma \sigma \alpha$ im Unterschied zu Sklavinnen bei Quintus noch in 6.159 und 14.38. Vgl. Od. 6.146. 


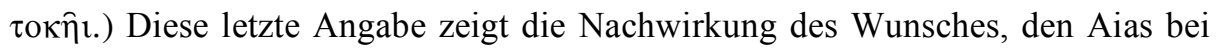

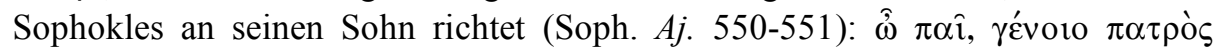

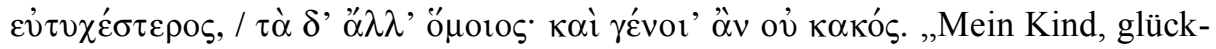
licher werde, als dein Vater war, / sonst aber ähnlich; schlecht wirst du dann wohl nicht sein.“27 Ähnlich wie bei Sophokles spielt auch Quintus auf die Dreieckskonstellation der Familie des Hektor an: Hektor - Andromache - Astyanax. ${ }^{28}$ Auf diese Entsprechung bezieht sich der Erzähler der Posthomerica in der Darstellung der Figur von Tekmessa, um sie Andromache anzunähern. Bei der allgemeinen Trauer um Aias in den Posthomerica ist Eurysakes nicht anwesend: Weil er noch

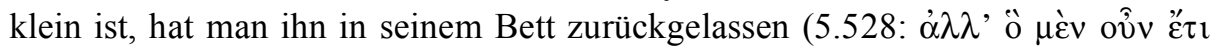

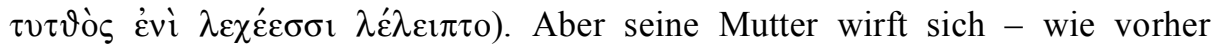
Teukros (5.502) - auf den lieben Toten, laut stöhnend wie sein Bruder in Vers 5.521, und in Staub gehüllt ${ }^{29}$ entstellt sie ihre schöne Gestalt. (5.529-530: $\ddot{\eta} \delta \dot{\varepsilon}$

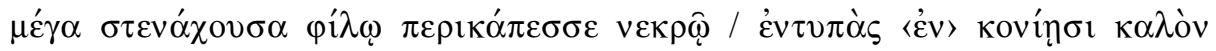
$\delta \varepsilon ́ \mu \alpha \varsigma$ $\alpha i \sigma \chi v ́ v o v \sigma \alpha$.) Im Gegensatz zu den Mitteilungen über Briseis (3.554-558)

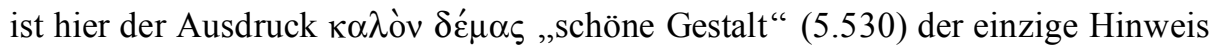
auf Tekmessas Schönheit. Das Hauptgewicht liegt darauf, dass Aias' Ehefrau und die Mutter seines Sohnes, nicht eine liebreizende Bettgenossin trauert. Die Beziehung des Aias zu Tekmessa sieht der Leser wie die des Hektor zu Andromache.

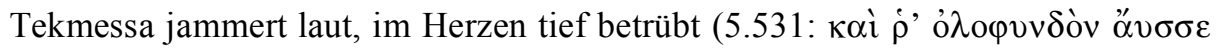

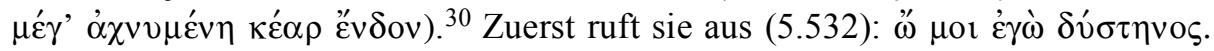
„Weh mir, der Unglücklichen!“ Dies begründet sie damit, dass Aias, den sie apostrophiert, nicht im Kampf von den Feinden, sondern von eigener Hand getötet wurde. Deswegen komme unvergessliches Leid über sie. Denn sie habe nicht erwartet, in Troja wegen seines Todes viel Jammer ${ }^{31}$ zu erleben. Dies alles

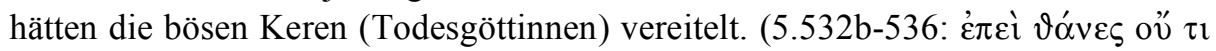

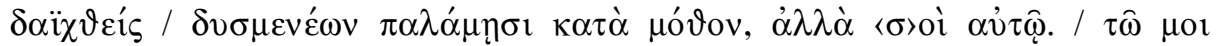

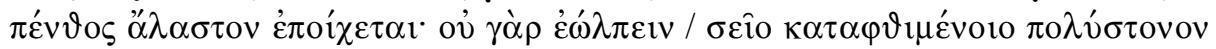

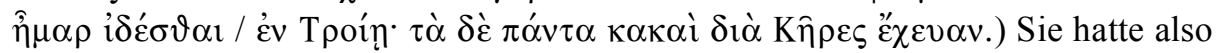
gehofft, er werde den Krieg überleben. Dass er, der gewaltige Kämpfer, den die

27 Übersetzung von Willige / Bayer (1990).

28 Zum Verhältnis zwischen den Versen 485-595 der sophokleischen Tragödie Aias und der ehelichen Homilie des 6. Buches der Ilias, das bereits die antiken Scholien zu Aias festgestellt haben (499, 501b, 514, 545a, 550 - siehe auch Christodoulos [1977]), siehe Kirkwood (1965) 56-60; Winnington-Ingram (1980) 31-32; Goldhill (1986) 186-187; Easterling (1984) 1-5; Synodinou (1986) 100-104; Poe (1987) 44-49; Garner (1990) 51-54; Zanker (1992) 22-23; Ormand (1996) 41-52; Garvie (1998) 169-181; Hesk (2003) 52-73.

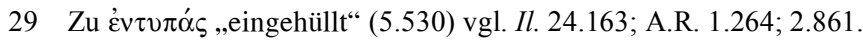

30 Vers 5.531 ähnelt 3.462; er kehrt 13.271 wörtlich wieder.

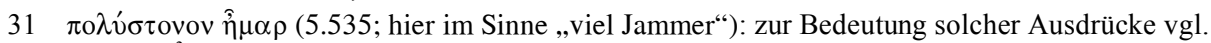
Fränkel $\left({ }^{3} 1968\right)$ 5-6. 
Troer nicht bezwingen konnten, sich selbst getötet hat, ist für sie ein ganz unerwarteter, doppelt schwerer Schicksalsschlag.

Mit Vers 5.537 beginnt der zweite Teil ihrer Rede: Tekmessa wünscht sich ähnlich wie Phoinix am Anfang seiner und Briseis am Ende ihrer Klagen -, sie wäre vor dem Tod des Aias gestorben. Denn ihr sei niemals ein schlimmeres Leid in die Seele gedrungen, auch nicht, als Aias sie zuerst mit anderen Beutefrauen aus ihrer Heimat und von ihren Eltern weggerissen habe, während sie viel geklagt habe, weil sie, zuvor eine ehrwürdige Herrin, zu einer Sklavin geworden sei.

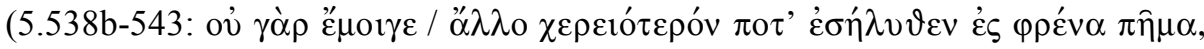

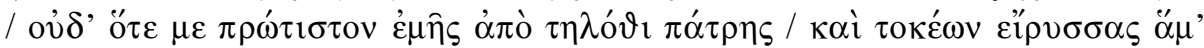

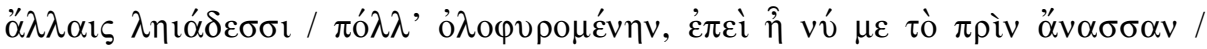

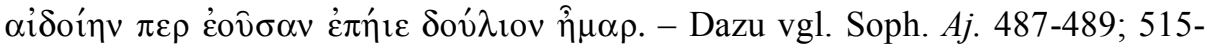
517.) Die Verse 5.538-539 stimmen wörtlich mit 3.465-466 in der Rede des Phoinix überein und 5.538b-539 (bzw. 3.465b-466) dem Sinne nach mit 3.561 in der Klage der Briseis. James / Lee ${ }^{32}$ bezeichnen die wörtliche Übereinstimmung der Verse 5.538-539 mit 3.465-466 als ,an unusually long repetition“. 5.538-539 sollen m.E. an die Rede des Phoinix, aber auch an die der Briseis erinnern und zeigen, dass der Tod des Aias für Tekmessa ebenso wie der des Achilleus für die beiden anderen ihr größtes Unglück ist. Insbesondere zeigt m.E. diese Wiederholung aus der Klagerede des Phoinix die Bedeutung des jeweiligen Verstorbenen für diese zwei Personen. Phoinix gehörte anfangs nicht zu der Familie des Achilleus. In seinem yóos in den Posthomerica betont er ähnlich wie in Il. 9.480b-484, dass er Zuflucht bei Peleus fand, der ihn herzlich aufnahm, ihm Geschenke gab und zum Herrscher über das dolopische Land machte. Sowohl die Ilias-Stelle wie auch die der Posthomerica (3.470-479) kulminieren nach dem Bericht des Phoinix über die Flucht aus seinem väterlichen Land und deren Beweggründe in der Schilderung seiner liebevollen Zuwendung zu Achilleus und von dessen Erziehung, so als ob Achilleus der leibliche Sohn des Phoinix gewesen wäre. Sowohl in der Ilias wie auch bei Quintus ist Phoinix kein einfacher Diener und Erzieher. In beiden Epen wird er aufgrund der Gaben des Peleus aus einem mittellosen Flüchtling zum Herrscher gemacht. Aias behandelte die Sklavin Tekmessa wie eine rechtmäßig angetraute Ehefrau, die im Haushalt bestimmte, und zeugte mit ihr ein Kind. Sowohl Phoinix wie auch Tekmessa wurden also von Fremden aufgenommen, die sie zu Familienmitgliedern machten. So etwas finden wir in der Rede der Briseis nicht, weder in einer Bemerkung des Erzählers noch ausdrücklich von ihr selbst.

Dass der Tod des Aias für Tekmessa ihr größtes Unglück ist, begründet sie anschließend. Aber nur sie erwähnt, dass sie durch den Mann, um den sie klagt,

32 James / Lee (2000) 141. 
einst selbst Leid erfahren hat. Sie fügt jedoch sogleich hinzu, weder der Verlust der herzerfreuenden Heimat noch der ihrer Eltern bekümmere sie so sehr wie sein Tod, weil Aias in allem ihr, der Armen, Herz zu erfreuen bestrebt war. (5.544-

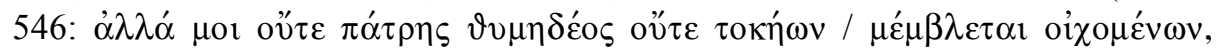

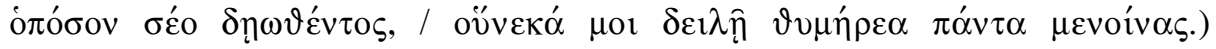

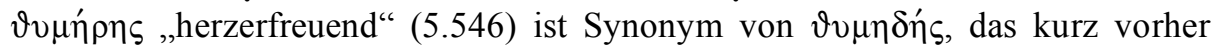
(5.544) als Beiwort von $\pi \alpha ́ \tau \rho \eta$ „Heimat“ erscheint: Aias suchte Tekmessa also die Heimat zu ersetzen. ${ }^{33}$ Vergleiche dazu ihre Frage bei Sophokles (Aj. 518): $\tau$ í

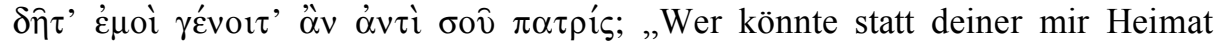
sein?“ Bei Quintus erläutert sie in den Versen 5.547-549 die allgemeine Aussage von Vers 5.546 folgendermaßen: Er habe sie zu seiner mit ihm harmonierenden

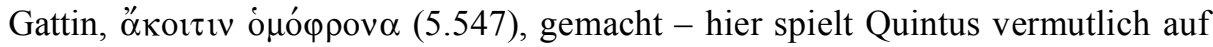
die berühmte Odyssee-Stelle (6.181-185) an, wo Odysseus die ó „Eintracht“ in der Ehe preist. ${ }^{34}$ Aias habe ihr versprochen, sie sogleich nach der Heimkehr zur Herrin von Salamis zu erheben - wodurch sie ihren früheren Status als ’’v $\alpha \sigma \sigma \alpha$ eines Reiches, nicht nur von Aias' Haushalt (5.523-525), wieder-

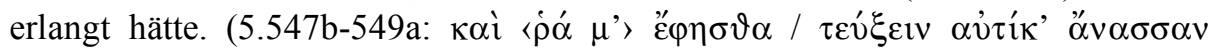

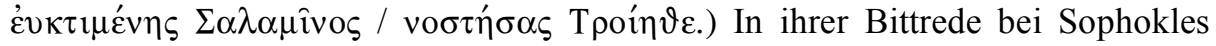
steht davon nichts: Dort hebt Tekmessa nur hervor, dass sie die Bettgenossin des

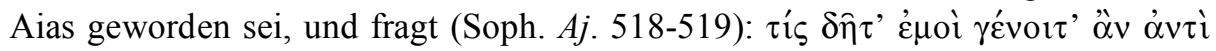

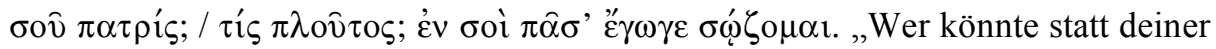
mir Heimat sein? Wer Reichtum? Bei dir bin ich ganz geborgen." Bei Quintus hat Aias also Tekmessa vom Status der Sklavin befreit, sie zu seiner Gattin gemacht und ihr noch weitere Erhöhung verheißen. Dieses Versprechen erinnert uns an das des Patroklos, das Briseis in Il. 19.297-299 hervorhebt, dass er sie mit Achilleus vermählen, sie nach Phthia bringen und dort die Hochzeit ausrichten wolle. All

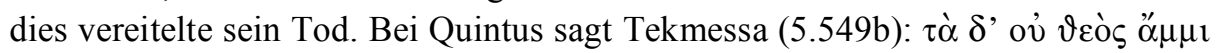
$\tau \varepsilon \dot{\lambda} \lambda \varepsilon \sigma \sigma \varepsilon v$. „Eine Gottheit hat uns dies nicht erfüllt.“ Der Leser weiß, dass es Athene war. Durch den Tod des Aias verliert Tekmessa die Hoffnung auf den von ihm selbst versprochenen, noch höheren sozialen Aufstieg. Sie befürchtet sogar tiefe Erniedrigung. Davon handelt der dritte Teil ihrer Rede: In den Versen 5.550-

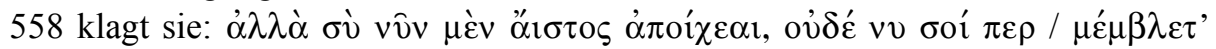

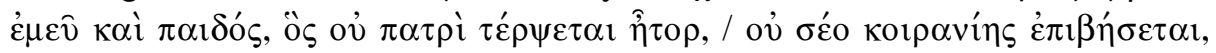

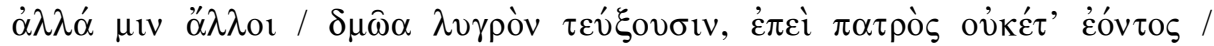

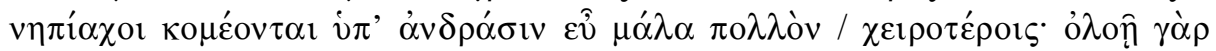

33 Vgl. auch James / Lee (2000) 142.

34 Das Adjektiv ómó $\rho \omega v$ „gleichgesinnt, einträchtig“ findet sich bei Quintus nur hier; das Partizip

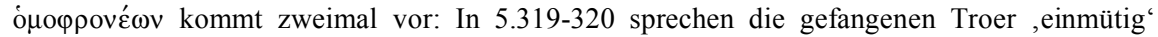
Odysseus die Waffen des Achilleus zu; in 10.425-427 erwähnt Oinone ihre einstige Hoffnung, immer , in Eintracht‘ mit Paris als Gatten leben zu können. 


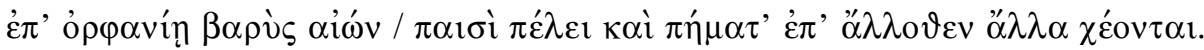

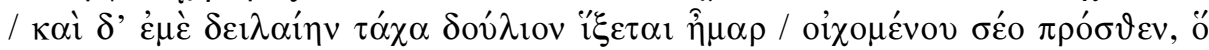

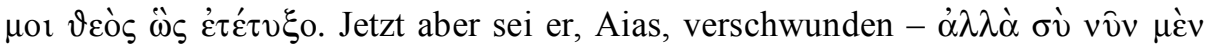

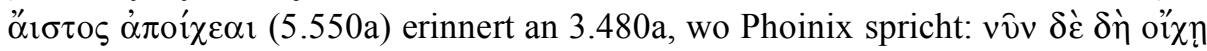
״' $1 \sigma \tau о \varsigma ;$; Er kümmere sich nicht um sie und den Sohn, ${ }^{35}$ der sich nicht im Herzen über den Vater freuen und nicht dessen Herrschaft erreichen werde, sondern andere würden ihn zu einem elenden Sklaven machen, ${ }^{36}$ weil nach dem Tode des Vaters die unmündigen Kinder von sehr viel schlechteren Männern betreut würden. Denn in der schlimmen Verwaisung sei das Leben für die Kinder schwer und von allen Seiten ergössen sich Leiden auf sie. Und zu ihr selbst, der Unglücklichen, werde bald der Tag der Sklaverei kommen, weil Aias, der ihr wie ein Gott gewesen sei, zuvor dahingegangen sei. Sie fürchtet vor allem für ihren Sohn. Briseis klagt bei Quintus am Ende ihrer Rede, jetzt werde ein anderer Achaier sie nach Sparta oder Argos bringen und sie werde als Dienstmagd schlimme Leiden erdulden. Sie hat keinen Sohn. Die Worte Tekmessas (5.550-558), in denen Mutterliebe dominiert, erinnern stärker an die beschwörenden Bitten, die sie bei Sophokles $(A j$. 492-513) an Aias richtet, sie und den Sohn vor der Knechtschaft bei seinen griechischen Feinden zu bewahren, ${ }^{37}$ als an die Klagen Andromaches (Il. 22.484b-506 und 24.725-745) über das künftige Los des Astyanax und ihr eigenes. Anders als Andromache, die in ihrem yóos von einer hypothetischen Situation spricht (vgl. Il. 22.487), hat Tekmessa die potentiellen Vormünder ihres Sohnes vor sich. Allein von ihnen hängt das künftige Los ihres Sohnes und ihr

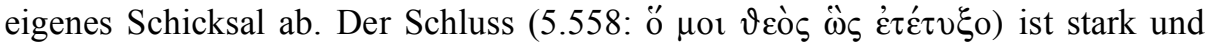
pointiert, und Tekmessa, anders als Briseis, bringt dieses höchste Lob erst hier zum Schluss, nachdem sie die Wichtigkeit des Aias steigernd erst für sich und dann für seinen Nachkommen begründet hat. Die oben genannte Stelle in der Tragödie (Soph. Aj. 492-513) bereitet die Rhesis des Aias in 545-582 vor, auf die Quintus mit Vers 5.527 angespielt hat: In den Versen 560-573 erteilt Aias Befehle, die das von Tekmessa befürchtete Unglück des Eurysakes verhindern sollen. Bei Sophokles trifft er also Vorsorge für seinen Sohn und damit implicite auch für

35 Tekmessa richtet hier ihre Klage in der Form eines indirekten Vorwurfs an den Verstorbenen, ähnlich wie Andromache zu Beginn und zum Schluss ihres yóos um den toten Hektor (vgl. Il. 24.725-726; 743-745).

36 Bemerkenswert ist die Antithese, die der Dichter mit der Futurform des Verbums $\tau \varepsilon v ́ \chi \omega$ zwischen Vers 5.548a und 5.553a aufstellt: $\tau \varepsilon v \xi_{\varepsilon} \varepsilon v \alpha \tau^{\prime} \tau^{\prime} \kappa^{\prime} \alpha^{\prime} v \alpha \sigma \sigma \alpha v$ (Aias - Tekmessa) / $\delta \mu \omega \hat{\omega} \alpha$

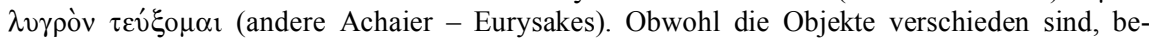
ziehen sich beide Ausdrücke sowohl auf Tekmessa wie auch auf Eurysakes.

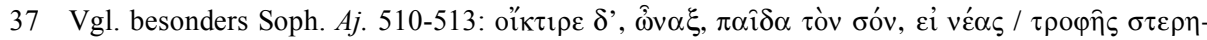

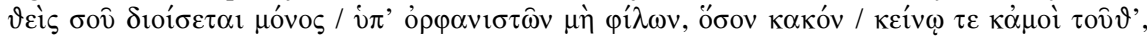

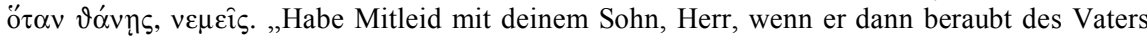
bei lieblosen Vormündern leben müsste, ohne dich; in welch ein Unglück stürzest du ihn und mich, wenn du stirbst!" 
dessen Mutter. ${ }^{38}$ Quintus hat ihn dies um Tekmessas Klagerede willen versäumen lassen. Hier finden wir anders als bei Sophokles einen starken Kontrast zwischen dem früheren ,herzerfreuenden' Verhalten des Aias und den schlimmen Folgen seines Versäumnisses, und das Leid Tekmessas ist vertieft. Dort, in der Tragödie, quälen sie Sorgen, aber sie kann Aias noch anflehen und hoffen, dass er sich von ihr umstimmen lässt. Bei Quintus kann sie dies nicht mehr, sie hat ihn endgültig verloren und ist verzweifelt. Ihre Rede richtet sich bis zum Schluss, auch noch mit dem letzten Satz, an den Toten. Tekmessa appelliert nicht an die anwesenden Achaier und der Dichter sagt nicht, dass sie in ihnen Mitleid erwecken wolle. Aber anders als bei Sophokles trauern sie alle um Aias, obwohl er sie töten wollte, und alle hören Tekmessas Worte. So ist es hier nicht unverständlich, dass Agamemnon sich ihr freundlich zuwendet. Er versichert ihr, niemand werde sie zu einer Sklavin machen, solange Teukros noch lebe und er selbst, sondern sie würden sie immer mit unzähligen Gaben wie eine Göttin ehren und auch ihren Sohn, wie wenn Aias noch lebte, der die Stärke der Achaier gewesen sei. Agamemnon äußert den Wunsch, Aias hätte nicht ganz Griechenland durch seinen Selbstmord Schmerz bereitet. Denn das zahllose Heer der Feinde habe ihn nicht

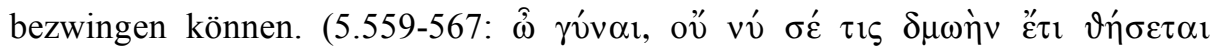

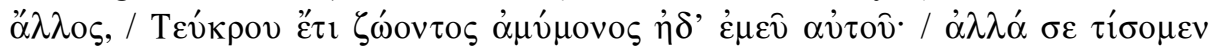

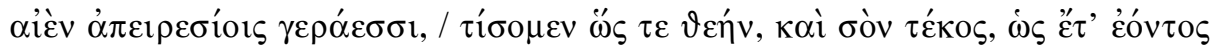

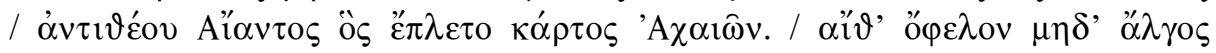

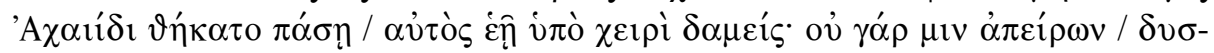

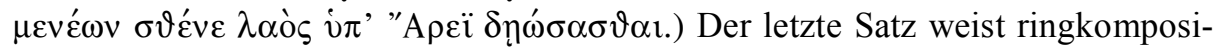
torisch auf den Anfang von Tekmessas Klagerede zurück. Agamemnon erkennt also die große Bedeutung des Aias für die Griechen voll an, und dieser Bedeutung wegen sollen Tekmessa und Eurysakes nicht nur vor der Sklaverei bewahrt, sondern auch hoch geehrt werden. Briseis aber erhält überhaupt kein Versprechen.

Es hat sich gezeigt, dass auch die Totenklage Tekmessas poetische Beziehungen zu früheren Dichterstellen aufweist und dass ihre Besonderheit sich durch Vergleich mit diesen voll erschließt. Die Trauerrede der Gattin bei Quintus übertrifft die Bittrede der Sklavin und Konkubine bei Sophokles, aber auch die Klage der Briseis bei Quintus.

38 Dazu vgl. Synodinou (1986) 102: „We could, of course, maintain that Ajax by providing for his son takes care indirectly of the mother of the child as well. Be that as it may, what counts from our perspective is the fact that Ajax "forgets" her at this crucial moment." Siehe auch March (1991-1993) 15: „Teucer is to take Eurysakes - and thus necessarily Tekmessa, since the boy is to be his mother's delight - home to Salamis $[\ldots]^{\text {“ }}$ 


\section{Oinones Klage (Q.S. 10.411-431)}

Oinone tritt in den Posthomerica nur im 10. Buch auf, und sie ist die einzige, die den Tod des geliebten Mannes nicht nur beklagt, sondern ihm auch nachfolgt. Ihre Selbsttötung am Schluss der zweiten Pentade bildet eine Analogie zu der des Aias im 5. Buch. ${ }^{39}$

Das Lebensende des trojanischen Prinzen Paris ist das Hauptthema des 10. Buches. Eine in den Posthomerica einmalige, kontrastreiche Szenenfolge hebt seinen Tod als Wendepunkt in Trojas Schicksal hervor. Paris wird in einer Schlacht schwer von Philoktetes verwundet. Kein Arzt kann ihn heilen. Er weiß aber, dass Oinone ihn zu retten vermag, wenn sie will. Darum geht er allein durch das Ida-Gebirge in ihr Haus und fleht sie um Hilfe an. Sie weist ihn jedoch wegen der tiefen Kränkung ihrer Liebe fort. Der Erzähler kündigt an, dass ihr bald nach Paris' Ende der Tod bevorsteht (10.329b-331). Während der Prinz auf dem Rückweg ist, sieht ihn die Göttin Hera vom Olymp aus und teilt ihren Dienerinnen mit, dass infolge seines Todes Troja seine Unzerstörbarkeit verlieren wird. Paris stirbt im Gebirge. Dort finden ihn Hirten und Nymphen und beklagen ihn. Seine Leiche wird nicht in die Stadt gebracht, aber ein Bote meldet in Troja das Ableben des Paris. Aus diesem Anlass reden hier zwei Frauen: Wie im 24. Buch der Ilias Hekabe und Helena über die Bedeutung von Hektors Lebensende für sie selbst sprechen, so bei Quintus über die von Paris' Tod, wobei Helena - ebenso wie die Troerinnen - ihn nur scheinbar betrauert. Aber bei Homer redet auch Andromache, Hektors Ehefrau. Für eine vollständige Entsprechung muss in den Posthomerica noch eine dritte, Paris nahe stehende Frau zu Wort kommen. Das kann nur Oinone, die von ihm verlassene Gattin, sein. Auch wegen der Ankündigung ihres Todes ist ihre Rückkehr in die Handlung notwendig.

In 10.411-412a berichtet der Erzähler, dass Oinone als Einzige aus starker

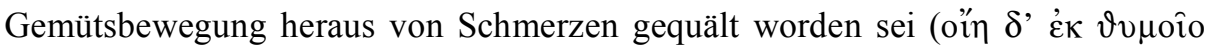

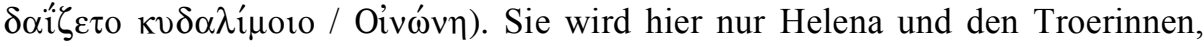
nicht Hekabe, entgegengesetzt. Ihre Trauer um Paris ist nach ihrer Ablehnung seiner Bitte um Heilung unvermittelt, aber nicht unverständlich. In der früheren Situation war ihre Liebe von Erbitterung über seine Untreue überlagert und erstarrt. Doch jetzt bewirkt sein Tod, dass die Liebe wieder auflebt und zugleich Leid entsteht. Oinone klagt nicht unter den Troerinnen, sondern liegt zu Hause und beklagt heftig das Ehebett ihres früheren Gatten. (10.412b-414: $\alpha \lambda \lambda{ }^{\prime}$ ov $\tau \imath$

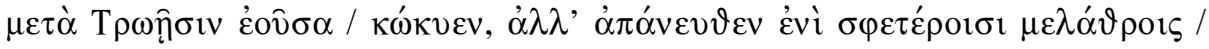

39 Vgl. Schmidt (1999) 147: „Quintus hat sein Werk so gestaltet, daß die Selbsttötungen des Aias und der Oinone nicht nur inhaltlich, sondern auch strukturell einander entsprechen." 


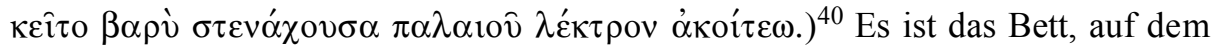
sie sich einst in Liebe mit ihm vereinigt hatte, das er dann jedoch für immer verließ.

In den Versen 10.415-422 lässt der Dichter nun - wie auch in 3.579b-581 und 7.229b-231 durch das Bild der Schneeschmelze in Od. 19.205-207 angeregt - ein Gleichnis folgen:

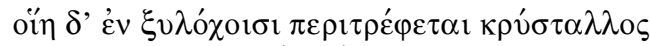

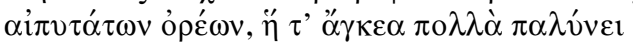

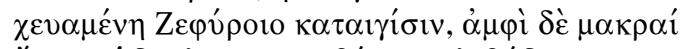

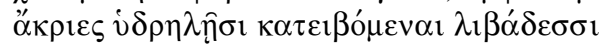

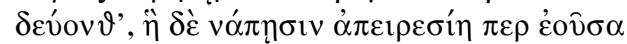

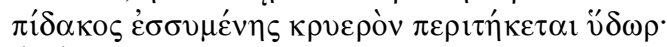

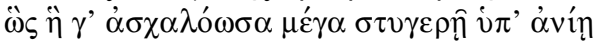

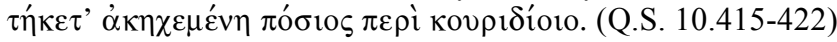

Wie sich im Dickicht sehr hoher Berge rings

Eis bildet, das viele Täler überzieht,

sich ausbreitend durch die Böen des Zephyros, ringsum aber die hohen

Bergspitzen, von strömendem Wasser überflossen,

nass werden und das Eis in den Tälern trotz seiner großen Masse

zu kaltem Wasser schmilzt, weil eine Quelle hineinstürzt ${ }^{41}$

so schmolz sie (Oinone), schwer bekümmert durch verhasstes Leid,

in ihrer Trauer um ihren rechtmäßigen Gemahl.

Für kurze Zeit versetzt das Gleichnis den Leser in eine Gebirgslandschaft. Es schildert in eindrucksvoller Weise sowohl die dortige Entstehung von Eis wie die auf den Höhen beginnende, hinab in die Täler sich fortsetzende und diese ganz durchdringende Eisschmelze, deren Urheber ${ }^{42}$ nicht genannt wird. ${ }^{43}$ Dieses Bild ist wieder eine Variation des Odyssee-Gleichnisses, erinnert aber auch an die beiden anderen in den Büchern 3 und 7 der Posthomerica. So regt es zum Vergleich und zur Erkenntnis der ihm eigenen Originalität an, mit der der Dichter, wie mir scheint, alle drei zu übertreffen sucht. Diese Originalität zeigt sich bereits in der detaillierten Beschreibung eines natürlichen Prozesses, der sich selbst in Gang zu setzen scheint und mit elementarer Kraft fortschreitend ungeheure Eismassen in Wasser verwandelt.

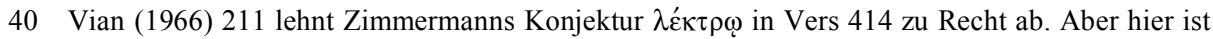
m.E. mit gemeint, dass Oinone auf diesem Bett liegt.

41 Zu den Versen 10.415-420 vgl. Vian (1969) 209 Anm. 5 zu S. 33; Hopkinson (1994a) 116.

42 Od. 19.206: Euros; Q.S. 3.581 und 7.230: Euros und Helios.

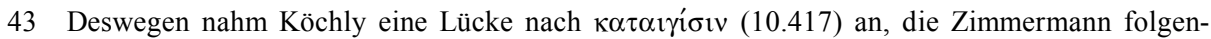

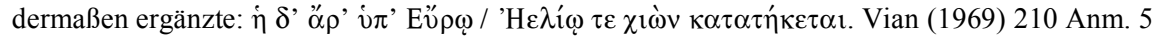
zu S. 33 wendet zu Recht dagegen ein: „La précision est superflue et manque d'ailleurs dans l'imitation que Tryphiodore (v. 189-191) fait de notre passage." 
Auch jedes der drei früheren Gleichnisse bezieht sich auf eine Frau - Penelope, Briseis, Deidameia -, die über den Verlust des geliebten Mannes trauert. Wie schon erwähnt, schmelzen in der Odyssee die schönen Wangen Penelopes wie Schnee aufgrund des Ostwinds, als sie beim Anhören der erfundenen Erzählung des Bettlers von seinem Zusammensein mit Odysseus Tränen um ihren Mann vergießt, der sich doch bereits in ihrer unmittelbaren Nähe befindet. Fränkel (1921) 33 hat diese Stelle m.E. zutreffend gedeutet: Penelopes Seele, die in langen, harten, öden Jahren wie unter einer Schneedecke gelegen habe, löse sich aus ihrer Starre, zu Tränen gerührt, wie der Schnee unter dem milden Hauch des warmen Windes schmelze. - Den Sinn des Gleichnisses in der Briseis-Partie bei Quintus habe ich bereits erklärt (siehe oben S. 193-194). - Im 7. Buch wird das Bild der Schneeschmelze nicht wie dort für Tränen, sondern dafür gebraucht, dass Deidameia vor Kummer um den Tod ihres Gatten Achilleus vergeht (7.231:

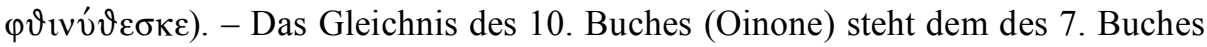
(Deidameia) insofern näher, als das Schmelzen auch nur auf Seelisches hinweist, nicht auf einen Tränenausbruch, der bei Oinone erst später erfolgt (10.421-422):

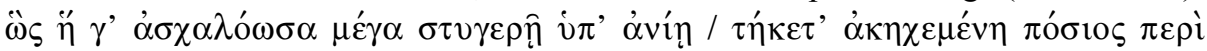
коvpı́íoı. „So schmolz sie, schwer bekümmert durch verhasstes Leid in ihrer Trauer um den rechtmäßigen Gemahl.“ Das ,Eis‘, das nach dem Treuebruch des Paris in ihrer Seele entstanden war und sich in der Härte gegen sein Flehen zeigte, schmilzt nun in ihrem Schmerz um den toten Gatten. Das ist wesentlich anders als bei Penelope und bei Briseis und Deidameia. Das Gleichnis überzeugt den Leser von der Aufrichtigkeit der Trauer Oinones um Paris im Gegensatz zu der nur vorgetäuschten Helenas und der Troerinnen und bereitet ihre Klagerede vor.

Diese Rede hat nur acht Verse (10.424-431), ist also kürzer als die von Hekabe und Helena und auch als die von Briseis und Tekmessa. Sie ist jedoch insofern bedeutungsvoller, als sie das Opfer des eigenen Lebens um der Wiedervereinigung mit Paris willen, einen Beweis größter Liebe, einleitet. $\mathrm{Zu}$ Beginn beklagt Oinone die böse Tat des Paris (d.h. Paris' Untreue; vgl. Q.S. 10.317 und 10.471-

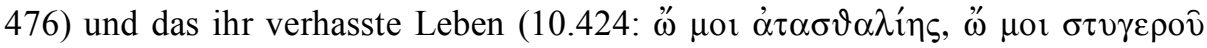

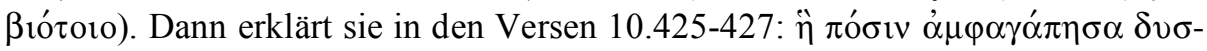

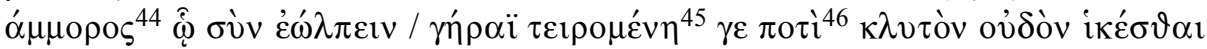

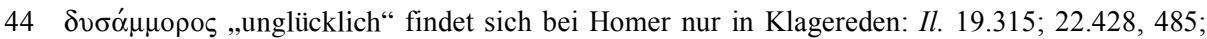
24.727; bei Q.S. 3.572 nennt sich auch Briseis so.

45 Vgl. Od. 24.233.

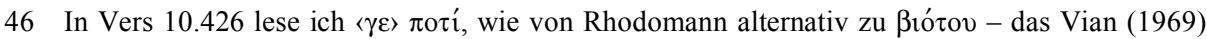
210 Anm. 6 zu S. 33 zu Recht ablehnt - vorgeschlagen. So druckt auch Pompella (1993) 126

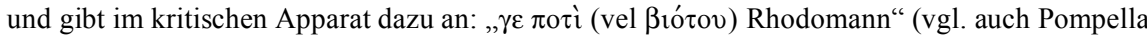
[2002] 168). 


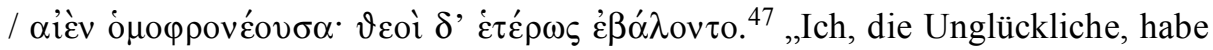
den Gatten mit Liebe umgeben und gehofft, / mit ihm zusammen, durch Alter entkräftet, in ständiger Eintracht zu der berühmten Schwelle des Hades zu gelangen; / die Götter aber haben es anders bestimmt." Quintus ändert hier die Worte,

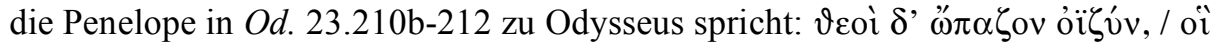

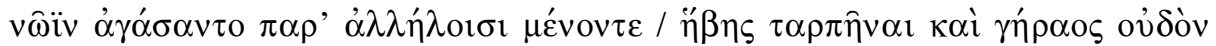

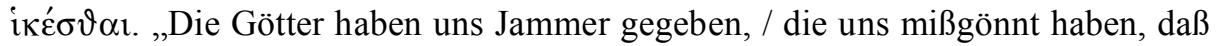
wir beieinander bleiben / und die Jugend genießen und zur Schwelle des Alters kommen sollten." ${ }^{48}$ Penelopes Vorstellung von einer vollkommenen Ehe wird bei Quintus überboten durch ausdrückliche Erwähnung des einträchtigen Zusammenlebens - das ist wieder wie schon in der Klagerede Tekmessas (5.547) eine An-

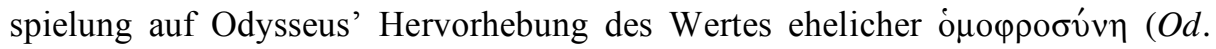
6.181-185) - und durch den Gedanken, an der Seite des Gatten nicht nur das Alter zu erleiden, sondern mit ihm auch ins Totenreich einzugehen. ${ }^{49}$ Paris ist nun gestorben. Sein Einlass in den Hades erfolgt jedoch erst, nachdem er bestattet ist. Daher steht für Oinone noch eine Möglichkeit offen, gemeinsam mit ihm dorthin zu kommen. Das Leben ist ihr verhasst: Dies hat sie bereits am Anfang gesagt (10.424b) und zeigt es aufs Neue in dem Wunsch (10.428-429): "̋s $\mu^{\prime}$ ó $\varphi \varepsilon \lambda o ́ v$ $\pi$ о $\tau \varepsilon$ K $\pi \varepsilon ́ \lambda \varepsilon \sigma \vartheta \alpha$ l. „Hätten mich doch die schwarzen Todesgöttinnen einst entrafft, / als ich ohne Alexandros sein sollte!" Zum dritten Mal erscheint ihr Lebensüberdruss und zugleich ihre Konsequenz daraus in ihrer abschließenden Erklärung (10.430-

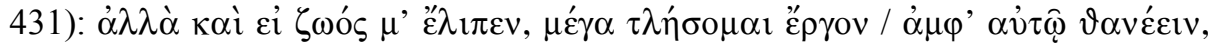

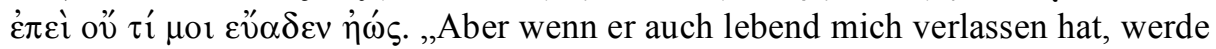
ich die große Tat - $\mu \varepsilon^{\prime} \gamma \alpha$ हैp pov - unternehmen, / bei ihm zu sterben, weil mir das

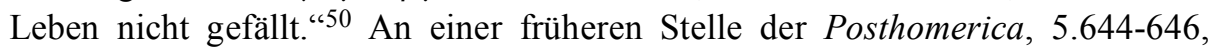

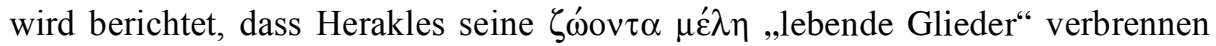
ließ, ó $\pi \pi$ ó $\tau$ ' है $\tau \lambda \eta \mu$ ' nicht wie er unerträgliche körperliche Schmerzen erleiden. Ihr Entschluss hat ausschließlich psychische Ursachen: Lebensüberdruss und das Verlangen nach endgültiger Wiedervereinigung mit Paris, beides aus Liebe; von Reue über die

47 Auch Q.S. 1.610b. Hopkinson (1994a) 117 nimmt wohl richtig an, Quintus habe die Lesart

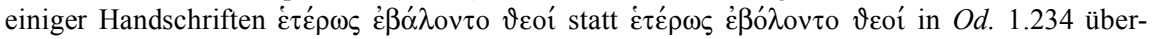
nommen. Vgl. auch Verg. Aen. 2.428: dis aliter visum. „Anders meinten es die Götter.“

48 Übersetzung von Schadewaldt (1958).

49 Die Verse 10.426 und $10.427 \mathrm{~b}$ variieren Wendungen anderer Odyssee-Stellen, 24.233a und 1.234 .

50 In 13.272-286 bittet Andromache die Argeier, sie von der Mauer oder von Felsen zu stürzen

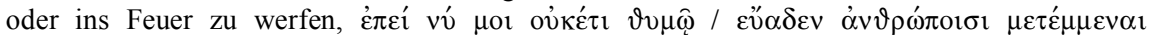
(13.283b-284a) „weil es mir nicht länger gefällt, unter den Menschen zu sein“. Ähnlich Dido bei Verg. Aen. 4.451: taedet caeli convexa tueri. „Sie hasst es, das Himmelsgewölbe zu schauen." 
Ablehnung seiner Bitte finden wir weder in den Worten des Erzählers noch in ihren eigenen eine Spur. Aber wie Herakles will auch sie sich lebendig verbrennen lassen.

Nach der Rede wird die Beschreibung der einsamen Trauer Oinones um Paris abgeschlossen. Sie vergießt nun Tränen, die sie wie Medea bei A.R. 3.1118-1119 - wo Od. 8.531 und 16.219 nachwirken - zum Erbarmen niederströmen lässt. Während sie des Gatten gedenkt, der sein Verderben vollendet hat, ,schmilzt ${ }^{\text {‘ sie }}$ wiederum, jedoch nicht so wie vorher in 10.415-420, sondern wie Wachs im Feuer. Dieser Vergleich begegnet uns in früherer Dichtung bei Asklepiades ( $A P$ 5.210.2) und Theokrit (Id. 2.28-29), auf Männer bezogen, die von Liebesverlangen erfasst sind, und bei Quintus (7.387-388), wo Deidameia, als Neoptolemos sie verlässt, aus Mutterliebe von Schmerz überwältigt wird. An der Stelle im 10. Buch hat der Vergleich eine neue, zweifache Funktion: Zum einen hebt er die starke Wirkung des Gedenkens an den verstorbenen Ehemann hervor; zum anderen deutet er auf Oinones Tod im Feuer des für Paris errichteten Scheiterhaufens

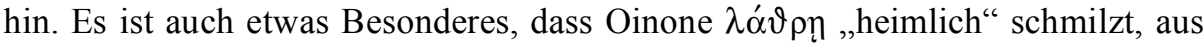
Scheu vor ihrem Vater und ihren Dienerinnen. Sie will von ihrem Vorhaben nicht abgehalten werden. Daher wartet sie, bis die Nacht sich ausgebreitet hat. Als alle anderen schlafen, verlässt sie das Haus und eilt, von der Todesgöttin (Ker) und von Aphrodite, d.h. von Liebe getrieben, ohne Furcht vor wilden Tieren durchs Gebirge zum Ort, wo der Holzstoß mit der Leiche des Paris bereits lodert. Sie verhüllt ihr Gesicht, springt wortlos ins Feuer und verbrennt mit ihrem Gatten. Dieser Freitod durch Verbrennung hat bei Vergil eine Entsprechung in Didos Selbstmord, wobei die Unterschiede zwischen diesen beiden Gestalten größer als die Ähnlichkeiten sind. Die Gebeine von Paris und Oinone werden in einer einzigen Urne bestattet. Der Erzähler vergleicht Oinone mit Euadne, die sich ebenfalls auf den Scheiterhaufen ihres Gemahls stürzte (vgl. bes. Euripides, Supplices 980-1072). Aber Kapaneus hatte sie nicht um einer anderen Frau willen verlassen. So übertrifft Oinone durch ihren Freitod aus Liebe nicht nur Penelope, auf die der Dichter wiederholt anspielt, sondern auch Euadne - aber erst bei Quintus. Innerhalb der Posthomerica ist die Darstellung ihrer Reaktion auf den Tod des geliebten Mannes nach derjenigen der Briseis und der Tekmessa poetisch am meisten ausgestaltet.

Das Schicksal der Oinone im 10. Buch entspricht in weiten Teilen dem des Aias im 5. Buch. Vor seinem Selbstmord erhebt Aias eine Klage in der Form eines Monologs (5.465-481). Ein Monolog ist auch Oinones Totenklage. ${ }^{51}$ Sowohl Aias wie Oinone litten unter Entehrung - der eine durch die Atriden, die andere durch Paris -; dies begründete ihren Groll. Aias und Oinone entscheiden

$51 \mathrm{Zu}$ den Monologen in den Posthomerica vgl. Elderkin (1906). 
sich, Selbstmord zu begehen: Aias, um sein $\kappa \lambda$ ćos, seinen „Ruhm“, nach seiner Verblendung zu retten, aber zum Nachteil seiner Familie. Oinone begeht Selbstmord aus Liebe zu dem Manne, der sie verachtete (vgl. Q.S. 10.471-476), um sich mit ihm im Hades wiederzuvereinigen. Durch diese Tat gewinnt Oinone in den Posthomerica ein $\kappa \lambda$ źo $\varsigma$ unter den Frauen, das der ehelichen Liebe und Gattentreue - ein $\kappa \lambda \lambda_{\varepsilon}$ 's, das verglichen mit dem der Andromache, der Penelope und der Euadne höher zu bewerten ist.

Das Streben des Dichters nach Antithetik zwischen Oinone und Helena darf nicht unerwähnt bleiben. Helena spiegelt bei den Troern Trauer um Paris vor. Ihre Rede bei Q.S. 10.392-405 ist ein Selbstgespräch, in dem sie nicht eigentlich den Tod ihres Gatten beklagt, sondern die Situation, in die sie durch seinen Tod versetzt wurde. Sie beklagt in 10.407-408a die Schuld, die sie auf sich geladen hat, als sie ihm folgte, gesteht sie sich selbst gegenüber jedoch nicht ein. In 14.156-158 versteigt sie sich Menelaos gegenüber sogar zu der Behauptung, sie sei von Alexandros und den Troern während seiner Abwesenheit mit Gewalt gegen ihren Willen entführt worden. In ihrem Selbstgespräch kommt sie zu dem Schluss, dass ihr die Troer die Schuld an Ehebruch und Krieg vorwerfen werden, weil sie Paris gefolgt ist. In der griechischen Mythologie wird ihre und Menelaos' Rückkehr nach Sparta und ihr dortiges Weiterleben als Königin an seiner Seite beschrieben. Die einzige Strafe erlegt ihr Quintus mit der großen Furcht auf; eine Art poetischer Gerechtigkeit, zugleich aber Ironie.

Oinones Selbstmord steht in gegensätzlicher Entsprechung zu dem des Aias im 5. Buch insofern, als dieser Held sich aus Hass tötet; er flucht darin dem Odysseus, Agamemnon und den anderen Achaiern und fragt:

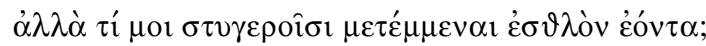

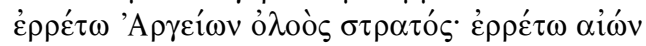

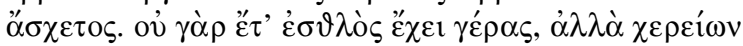

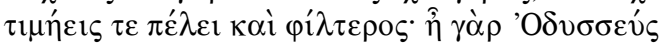

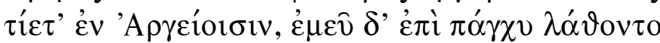

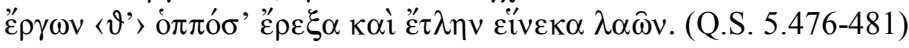

Warum soll ich als ein Edler unter Verhassten existieren?

Weiche, verfluchtes Heer der Argeier; weiche, Leben,

das ich nicht ertragen kann. Denn der Edle hat keine Ehre mehr, sondern

der Schlechtere

wird geehrt und ist beliebter (als der Edle); denn Odysseus genießt gewiss

Ehre unter den Argeiern, mich aber und all die Taten,

die ich ihretwegen vollbrachte und das, was ich für sie ertragen habe, haben

sie ganz vergessen.

Beide Selbstmorde markieren das Ende des ersten und des zweiten Teils der Posthomerica. Oinones Klage, ihr Selbstmord und gemeinsame Verbrennung und 
Bestattung mit ihrem früheren Ehegatten heben auch den Tod des Paris heraus, den Tod des letzten berühmten trojanischen Helden in den Posthomerica, der das Ende des Trojanischen Krieges einleitet. Der Tod des Aias in den Posthomerica ist der letzte eines berühmten griechischen Kämpfers vor Trojas Eroberung und kennzeichnet einen kritischen Moment für die Achaier bis zum Ankommen des Neoptolemos, der an die Stelle seines Vaters Achilleus tritt.

Die Interpretation der drei Totenklagen dürfte gezeigt haben, dass sie eine Klimax bilden. Sie stehen aber nicht nur in Beziehung zueinander, sondern auch zu älteren Dichterstellen, die in Erinnerung gerufen und zugleich abgewandelt werden. Diese Intertexte dienen besonders durch ihre abweichende Integration im Text des Quintus auch dazu, das Verhältnis dieser Frauen zu ihren geliebten Verstorbenen steigernd zu beleuchten: von der nicht ehelichen Beziehung der Briseis zu Achilleus über die eheähnliche der Tekmessa zu Aias bis zu der ehelichen Beziehung der Oinone zu Paris. Vor dem Hintergrund dieser Stellen tritt das von Quintus geschaffene Neue hervor. Es handelt sich offensichtlich um eine ganz bewusste poetische Technik. Dabei vollziehen die gebildeten Leser des Quintus durch das intertextuelle Aufrufen das Bestreben des Dichters nach, das jeweilige Modell zu übertreffen, was natürlich aemulatio ist. 
